\title{
Patient profile and periprocedural outcomes of bioresorbable vascular scaffold implantation in comparison with drug-eluting and bare-metal stent implantation. Experience from ORPKI Polish National Registry 2014-2015
}

\author{
Łukasz Rzeszutko ${ }^{1}$, Tomasz Tokarek², Zbigniew Siudak², Artur Dziewierz¹, Krzysztof Żmudka², Dariusz Dudek ${ }^{2}$ \\ ${ }^{1} 2^{\text {nd }}$ Department of Cardiology, Institute of Cardiology, Jagiellonian University Medical College, Krakow, Poland \\ ${ }^{2}$ Department of Interventional Cardiology, Institute of Cardiology, Jagiellonian University Medical College, Krakow, Poland
}

Adv Interv Cardiol 2016; 12, 4 (46): 321-328

DOI: $10.5114 /$ aic.2016.63632

\begin{abstract}
A bstract
Introduction: There are limited data on the comparison of bioresorbable vascular scaffold (BVS) and drug-eluting stent (DES)/ bare-metal stent (BMS) implantation in an unselected population of patients with coronary artery disease.

Aim: To compare the periprocedural outcomes and patient profile of BVS and DES/BMS implantation in an all-comer population from the ORPKI Polish National Registry.

Material and methods: A total of 141,324 consecutive patients from 151 invasive cardiology centers in Poland were included in this prospective registry between January 2014 and June 2015. Periprocedural data on patients with at least one BVS (Absorb, Abbott Vascular, Santa Clara, CA, USA), DES or BMS (all available types) implantation in de novo lesions during index percutaneous coronary intervention for stable angina (SA) or acute coronary syndrome were collected.

Results: Bioresorbable vascular scaffold was the most often used in patients with SA, in single-vessel disease and in younger male patients. Bioresorbable vascular scaffold implantation was significantly more often associated with periprocedural administration of ticagrelor/prasugrel $(6.8 \%$ vs. $3.6 \% ; p=0.001)$ and use of intravascular ultrasound and optical coherence tomography in comparison with the DES/BMS group ( $2.8 \%$ vs. $0.6 \%$ and $1.8 \%$ vs. $0.1 \%$, respectively; $p=0.001$ for both). The incidence of periprocedural death was significantly lower in the BVS group than the DES/BMS group ( $0.04 \%$ vs. $0.32 \% ; p=0.02)$, but this difference was no longer significant after adjustment for covariates. On the other hand, coronary artery perforation occurred significantly more often during BVS delivery ( $0.31 \%$ vs. $0.12 \% ; p=0.01)$, and BVS implantation was identified as an independent predictor of coronary artery perforation in multivariate logistic regression analysis ( $\mathrm{OR}=6.728,95 \% \mathrm{Cl}: 2.394-18.906 ; p=0.001)$.

Conclusions: Patients treated with BVS implantation presented an acceptable safety and efficacy profile in comparison with the DES/BMS group. However, lower risk patients were the most frequent candidates for BVS implantation.
\end{abstract}

Key words: bioresorbable vascular scaffold, metallic platforms, all-comers, de novo lesions, stable angina, acute coronary syndrome, registries.

\section{Introduction}

Current guidelines recommend coronary stenting with new-generation drug-eluting stents (DES) for most indications of percutaneous coronary intervention (PCI) [1]. However, new-generation DES have not managed to address all the limitations of metallic stents [1]. These limitations may include caging of the vessel, impairment of vasomotion, chronic inflammation, late expansive re- modeling, late thrombosis, potential preclusion of surgical revascularization and interference with magnetic resonance, imaging causing the blooming effect [2-6]. A bioresorbable vascular scaffold (BVS) ensures temporary vessel support with drug delivery to the endothelium without the potential long-term limitations of permanent metallic platforms $[4,5]$. Results from the ABSORB trials have confirmed the safety and efficacy of BVS implantation in rather non-complex lesions [7]. However,

\section{Corresponding author:}

Prof. Dariusz Dudek MD, PhD, Department of Interventional Cardiology, Institute of Cardiology, Jagiellonian University Medical College, 17 Kopernika St, 31-501 Krakow, Poland, phone: +48 1242471 81, e-mail: mcdudek@cyfronet.pl

Received: 16.08.2016, accepted: 6.11.2016. 
there are still limited data on BVS versus metallic stent implantation in an unselected "real-world" population, both in terms of current use profile and periprocedural outcomes.

\section{Aim}

The aim of this study was to compare the periprocedural outcomes and patient profiles of BVS and DES/BMS implantation in an all-comer population from the ORPKI Polish National Registry.

\section{Material and methods}

All obtained data were stored in the electronic database of National PCI Registry (ORPKI) operated by the Jagiellonian University Medical College in Krakow. ORPKI is a national registry collecting data on all percutaneous procedures in interventional cardiology performed in Polish ORPKI is a national registry collecting data on all percutaneous procedures in interventional cardiology performed on Polish territory [8]. This registry is a single-arm prospective observational study. Between January 2014 and June 2015, it enrolled 141,324 consecutive patients from 151 invasive cardiology centers in Poland. Patients with at least one BVS (Absorb, Abbott Vascular, Santa Clara, CA, USA), DES or BMS (all available types) implantation in de novo lesions during index $\mathrm{PCl}$ for stable angina (SA) or acute coronary syndrome (ACS) were included. A flow chart of the patients is presented in Figure $1 \mathrm{~A}$. All procedures were carried out according to current standards of $\mathrm{PCl}$. No further evaluation or follow-up was performed after hospital discharge. The full range of sizes and lengths for both BVS and DES/BMS were available during the study period in all participating centers. The decision to implant a BVS rather than a DES/BMS was the operator's choice according to stent instructions. However, it was recommended for the purpose of this registry to qualify for Absorb BVS implantation according to a prespecified algorithm (Figure $1 \mathrm{~B}$ ). Adverse events were diagnosed at the operator's discretion according to definitions in current ESC guidelines. The Independent Clinical Endpoint Committee was not involved in adverse events classification and validation of definitions. All patients provided informed consent for the procedure. The study complied with ethical principles for clinical research based on the Declaration of Helsinki with later amendments. No funding was used to support this registry.

\section{Statistical analysis}

Standard descriptive statistics were used in the analysis. Quantitative variables were described using mean \pm standard deviation. Categorical variables were presented

B

Algorithm of the patient's qualification for ABSORB BVS implantation

282136 consecutive patients collected prospectively from 151 invasive cardiology centres in Poland between January 2014 and June 2015 (ORPKI registry)

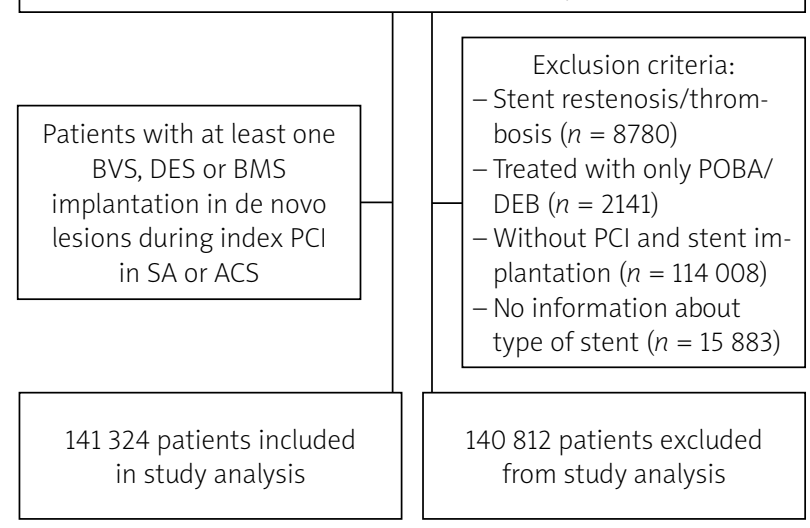

1. Patients $<67$ year old, or older, but active style of life. Yes $\square$ No $\square$

2. Significant risk of future revascularizations $\quad$ Yes $\square$ No $\square$

- diffused disease or long lesions,

- multiple non-significant stenoses,

- multiple risk factors,

to facilitate/having the option for the future interventions

(both percutaneous and cardiosurgery).

3. Long lesions for PCI to avoid "full metal jacket"

4. Lesions with location of potential coronary by-pass placement:

- middle segment LAD,

- distal segments of RCA, CX,

- middle, distal segments of OM.

5. Lesions "on the bend" to avoid straightening natural curvature of the artery.

6. Multivessel CAD qualified for $\mathrm{PCl}$, especially patients, who have a high probability of full revascularization with bioresorbable scaffolds or partial revascularization, but in prognostically important localizations (proximal segments, LAD, potential by-pass localization).

Please consider to use the ABSORB BVS in the case of any above criteria is fulfilled and if there is no angiographic contradictions for the use of ABSORB BVS.

Figure 1. Flow chart of the patients (A) and algorithm of the patient's qualification for ABSORB BVS implantation (B) 
Table I. Baseline patient characteristics

\begin{tabular}{|c|c|c|c|}
\hline Parameter & BVS $(N=2,258)$ & DES and BMS $(N=139,066)$ & $P$-value \\
\hline Male gender & $1,597(70.7 \%)$ & $93,846(67.5 \%)$ & 0.001 \\
\hline Age [years] & $59.97 \pm 10.6$ & $66.79 \pm 10.8$ & 0.001 \\
\hline Diabetes mellitus & $437(19.4 \%)$ & $37,989(27.3 \%)$ & 0.001 \\
\hline Previous stroke & $37(1.6 \%)$ & 4,666 (3.4\%) & 0.001 \\
\hline Previous MI & $645(28.6 \%)$ & $39,802(28.6 \%)$ & 0.9 \\
\hline Previous CABG & $75(3.3 \%)$ & $7,979(5.7 \%)$ & 0.001 \\
\hline Previous PCI & 856 (37.9\%) & $45,119(32.4 \%)$ & 0.001 \\
\hline Smoking & $517(22.9 \%)$ & $27,997(20.1 \%)$ & 0.002 \\
\hline Arterial hypertension & $1,581(70.0 \%)$ & $100,494(72.3 \%)$ & 0.02 \\
\hline CKD & $50(2.2 \%)$ & $7311(5.3 \%)$ & 0.001 \\
\hline
\end{tabular}

BMS - bare metal stent, BVS - bioresorbable vascular scaffold, CABG - coronary artery bypass grafting, CKD - chronic kidney disease, DES - drug-eluting stent, $\mathrm{MI}$ - myocardial infarction, $\mathrm{PCl}-$ percutaneous coronary intervention.

as counts and percentages. The level of statistical significance was set at $p<0.05$. The Mann-Whitney $U$ test (for non-normal distribution of data) or unpaired (two-sample) Student's t-test (for normally distributed data) was applied for continuous variables. The $\chi^{2}$ test was used for categorical (nominal and dichotomous) variables. In addition, multivariate logistic regression analysis was performed to find independent predictors of periprocedural death and perforation of the coronary artery. Forward selection in logistic regression analysis with a probability value for covariates to enter the model was set at the 0.05 level. All baseline and procedural characteristics were tested. Results were presented as odds ratios (OR) with $95 \%$ confidence intervals $(\mathrm{Cl})$. All analyses were carried out with Statistica 10 (StatSoft, Inc. Tulsa, OK, USA).

\section{Results}

Scaffold implantation was performed in 2,258 patients. Metallic stents were used in 139,066 procedures. Bioresorbable vascular scaffold was more often used in patients with SA, in single-vessel disease and in younger male patients (Tables I and II). Diabetes mellitus, arterial hypertension, previous stroke, chronic kidney disease and previous coronary artery bypass grafting were significantly less frequently reported in patients with BVS implantation as compared to the DES/BMS group. Incidence of BVS delivery to the left anterior descending (LAD) coronary artery was significantly higher as compared to the DES/BMS group (54.3\% vs. $35.9 \%$; $p=0.001$ ). The right radial access was the most common during $\mathrm{PCl}$, with a higher rate of its use in BVS patients as compared to DES/BMS patients (62.5\% vs. $50.2 \%$; $p=0.001)$. Overall, 165,188 metallic stents were implanted in the DES/BMS group (145,472 (88.1\%) DES; 19,716 (11.9\%) BMS; 3,355 (2\%) DES and BMS simultaneously in one patient) and 2,407 biodegradable scaffolds in the
BVS group. No differences were found between groups in terms of mean number of deployed stents per patient (BVS vs. DES/BMS: $1.07 \pm 0.3$ vs. $1.09 \pm 0.6 ; p=0.9$ ). Most often one scaffold was implanted in the BVS group (94\%), two were delivered in $5.5 \%$, three in $0.4 \%$ and four in $0.4 \%$ of all cases. Data describing the number of delivered scaffolds or stents to particular vessels are presented in Table III. No BVS implantation was reported in $48(31.8 \%)$ participating centers. Experience with 1-10 devices was noted in 63 (41.7\%), 10-50 were used in 29 (19.2\%) and 50-100 scaffolds were deployed in 5 (3.3\%)

Table II. Indications for percutaneous coronary intervention ( $p=0.001$ for all comparisons)

\begin{tabular}{|c|c|c|}
\hline Parameter & $\begin{array}{c}\text { BVS } \\
(N=2,247)\end{array}$ & $\begin{array}{l}\text { DES and BMS } \\
(N=138,440)\end{array}$ \\
\hline SA & $1,169(52)$ & $49,581(35.8)$ \\
\hline UA & $562(25)$ & $35,384(25.6)$ \\
\hline STEMI & $256(11.4)$ & $29,662(21.4)$ \\
\hline NSTEMI & $260(11.6)$ & $23,813(17.2)$ \\
\hline CTO & $54(2.4)$ & $431(0.3)$ \\
\hline \multirow[t]{2}{*}{ Bifurcation } & $72(3.2)$ & $7840(5.7)$ \\
\hline & $\begin{array}{c}\text { BVS } \\
(N=1,715)\end{array}$ & $\begin{array}{l}\text { DES and BMS } \\
(N=114,356)\end{array}$ \\
\hline Single-vessel disease & $1,150(67.1)$ & $54,882(48.0)$ \\
\hline LMCA & $6(0.4)$ & $137(0.1)$ \\
\hline $\begin{array}{l}\text { Multi-vessel disease } \\
\text { without LMCA }\end{array}$ & $530(30.8)$ & $53,678(47.0)$ \\
\hline $\begin{array}{l}\text { Multi-vessel disease } \\
\text { with LMCA }\end{array}$ & $29(1.7)$ & $5,659(4.9)$ \\
\hline
\end{tabular}

BMS - bare metal stent, BVS - bioresorbable vascular scaffold, CTO - chronic total occlusion, DES - drug-eluting stent, LMCA - left main coronary artery, NSTEMI - non-ST-segment elevation myocardial infarction, SA - stable angina, STEMI - ST-segment elevation myocardial infarction, UA - unstable angina. 
Table III. Number of scaffolds or stents implanted in particular vessels

\begin{tabular}{lcccc} 
Parameter & $\begin{array}{c}\text { BVS }(\boldsymbol{N}=\mathbf{2 , 4 0 7 )} \\
\boldsymbol{n}(\%)\end{array}$ & BMS $(\boldsymbol{N}=\mathbf{1 9 , 7 1 6 )}$ & DES $(\boldsymbol{N}=\mathbf{1 4 5 , 4 7 2 )}$ & $\boldsymbol{P}$-value \\
\hline LMCA & $15(0.6)$ & $251(1.2)$ & $3,652(2.5)$ & 0.001 \\
\hline LAD & $1,306(54.3)$ & $4,726(24.0)$ & $54,630(37.6)$ & 0.001 \\
\hline CX & $538(22.4)$ & $5,065(25.8)$ & $36,970(25.4)$ & 0.001 \\
\hline RCA & $538(22.4)$ & $9,497(48.2)$ & $48,369(33.3)$ & 0.001 \\
\hline LIMA/RIMA & $2(0.1)$ & $18(0.1)$ & $295(0.2)$ & 0.001 \\
\hline SVG & $8(0.3)$ & $159(0.8)$ & $1,556(1.1)$ & 0.001
\end{tabular}

BMS - bare metal stent, BVS - bioresorbable vascular scaffold, Cx - circumflex, DES - drug-eluting stent, LAD - left anterior descending, LIMA/RIMA - left/right internal mammary artery, SVG - saphenous vein grafts, $R C A$ - right coronary artery.

participating catheterization laboratories. Over 100 BVS were delivered in only 6 (4.0\%) highly experienced invasive cardiology centers. The highest volume was represented by a catheterization laboratory with implantation of 190 scaffolds. A higher number of BVS utilization was noted in 2015 in comparison with corresponding months of 2014. The lowest scaffold deployment was reported during July-August and at the end of 2014. The mean number of implanted scaffolds was $21.9 \pm 183.9$ per catheterization laboratories with experience in BVS utilization. Periprocedural therapy used during $\mathrm{PCl}$ is shown in Table IV. Thrombolysis in Myocardial Infarction flow before and after $\mathrm{PCl}$ is demonstrated in Figure 2. Bioresorbable vascular scaffold implantation was significantly

Table IV. Percutaneous coronary intervention details

\begin{tabular}{|c|c|c|c|}
\hline Parameter & BVS $(N=2,258)$ & DES and BMS $(N=139,066)$ & $P$-value \\
\hline Radiation dose [mGy] & $1,144.6 \pm 852.2$ & $1,171.4 \pm 1,008.6$ & 0.02 \\
\hline Contrast volume $[\mathrm{ml}]$ & $169.2 \pm 69.7$ & $178.4 \pm 77.6$ & 0.001 \\
\hline IVUS & $63(2.8 \%)$ & $817(0.6 \%)$ & 0.001 \\
\hline OCT & $40(1.8 \%)$ & $132(0.1 \%)$ & 0.001 \\
\hline Rotablation & $5(0.2 \%)$ & $610(0.4 \%)$ & 0.1 \\
\hline Aspiration thrombectomy & $65(2.9 \%)$ & $5,991(4.3 \%)$ & 0.001 \\
\hline Aspiration thrombectomy in STEMI patients & $42(16.4 \%)$ & $5,115(16.4 \%)$ & 1.0 \\
\hline \multicolumn{4}{|l|}{ Antiplatelet and antithrombotic therapy: } \\
\hline ASA administered during $\mathrm{PCl}$ & $647(28.7 \%)$ & $45,095(32.4 \%)$ & 0.001 \\
\hline $\mathrm{P}_{2 \mathrm{Y}_{12}}$ inhibitors before and during $\mathrm{PCl}$ & 2,258 & 139,066 & 0.001 \\
\hline Clopidogrel & $2,106(93.2 \%)$ & $134,124(96.4 \%)$ & 0.001 \\
\hline Ticagrelor & $99(4.4 \%)$ & $3,899(2.8 \%)$ & 0.001 \\
\hline Prasugrel & $53(2.4 \%)$ & $1,043(0.8 \%)$ & 0.001 \\
\hline GP IIb/IIla inhibitors & $11(0.5 \%)$ & $413(0.3 \%)$ & 0.1 \\
\hline Abciximab & $2(18.2 \%)$ & $142(34.4 \%)$ & 0.1 \\
\hline Eptifibatide & $9(91.8 \%)$ & $257(62.2 \%)$ & 0.1 \\
\hline Tirofiban & $0(0.0 \%)$ & $14(3.4 \%)$ & 0.1 \\
\hline UFH & $2,034(90.1 \%)$ & $118,440(85.2 \%)$ & 0.001 \\
\hline Bivalirudin & $8(0.4 \%)$ & $1,041(0.8 \%)$ & 0.03 \\
\hline LMWHS & $79(3.5 \%)$ & $5,476(3.9 \%)$ & 0.3 \\
\hline
\end{tabular}

ASA - acetylsalicylic acid, BMS - bare metal stent, BVS - bioresorbable vascular scaffold, DES - drug-eluting stent, FFR - fractional flow reserve, IVUS - intravascular ultrasound, LMWHS - low-molecular-weight heparins, OCT - optical coherence tomography, UFH- unfractionated heparin, GP-glycoprotein. 
A

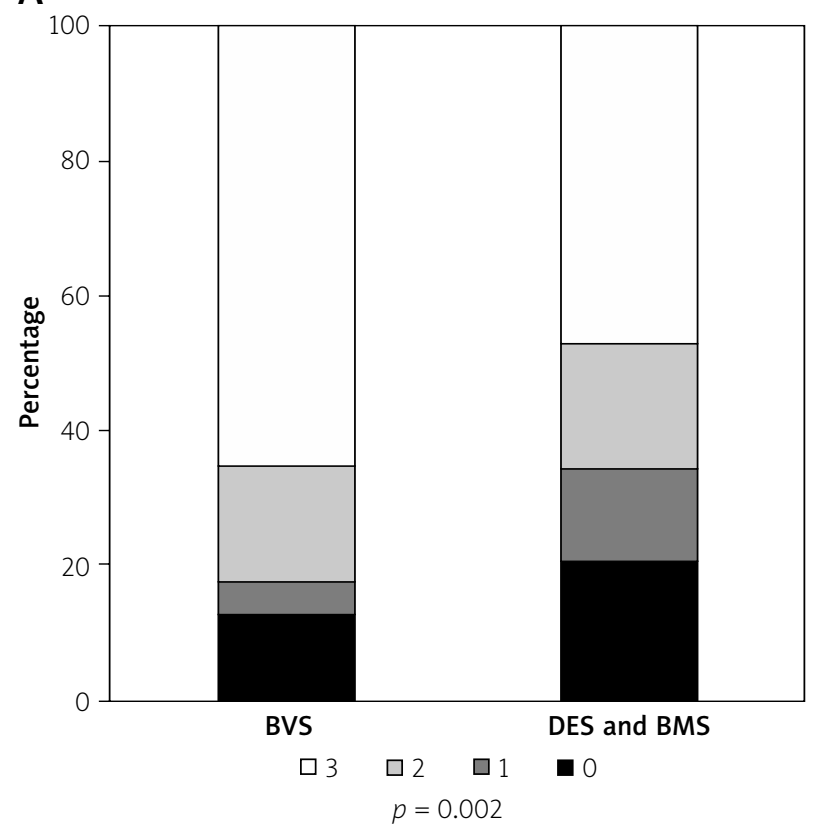

B

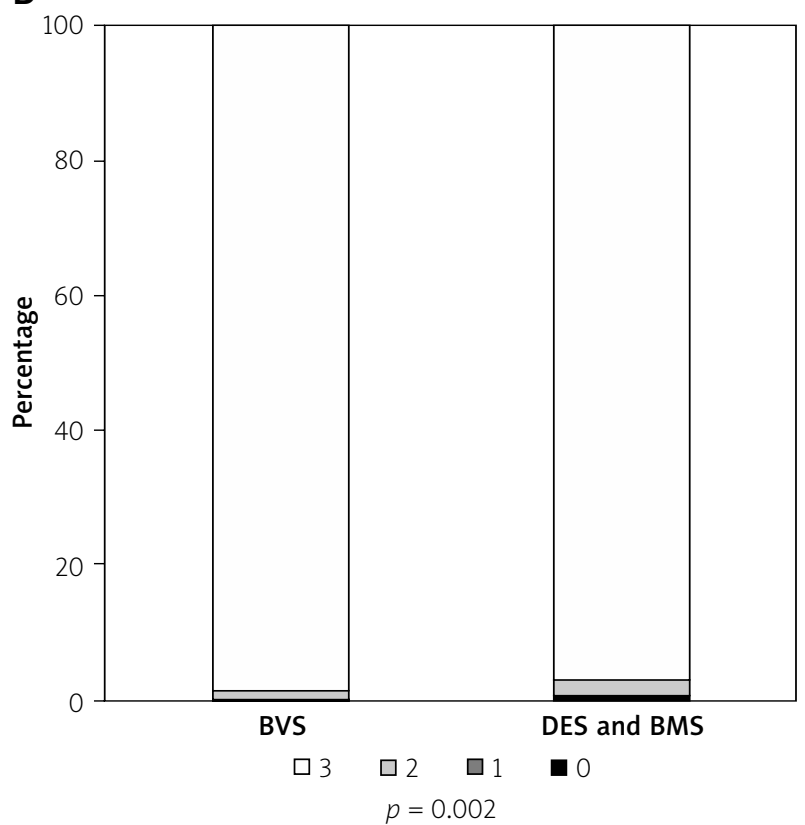

Figure 2. Thrombolysis in myocardial infarction before (A) and after (B) percutaneous coronary intervention

more frequently associated with periprocedural administration of ticagrelor/prasugrel (6.8\% vs. 3.6\%; $p=0.001)$ and use of intravascular ultrasound (IVUS) and optical coherence tomography (OCT) in comparison with the DES/BMS group $(2.8 \%$ vs. $0.6 \%$ and $1.8 \%$ vs. $0.1 \%$, respectively; $p=0.001$ for both). There were no differences between the BVS group and the DES/BMS group in terms of incidence of periprocedural events such as myocardial infarction ( $0.0 \%$ vs. $0.1 \% ; p=0.1)$, no-reflow $(0.35 \%$ vs. $0.45 \% ; p=0.5)$, vascular access site bleeding (0.09\% vs. $0.12 \% ; p=0.7)$, sudden cardiac arrest $(0.2 \%$ vs. $0.4 \%$; $p=0.2)$ or allergic reactions $(0.09 \%$ vs. $0.15 \% ; p=0.4)$. Higher incidence of perforation of coronary artery was reported in the BVS group ( $0.31 \%$ vs. $0.12 \% ; p=0.01)$, but periprocedural death occurred less frequently in patients treated with BVS $(0.04 \%$ vs. $0.32 \% ; p=0.02)$. In the logistic regression analysis age $(\mathrm{OR}=1.028,95 \% \mathrm{Cl}$ : $1.006-1.05 ; p=0.01)$ and BVS implantation $(\mathrm{OR}=6.728$, 95\% Cl: 2.394-18.906; $p=0.001$ ) were identified as independent predictors of perforation of the coronary artery. On the other hand, male gender $(\mathrm{OR}=0.525,95 \% \mathrm{Cl}$ : $0.326-0.847 ; p=0.008)$ and $\mathrm{TIMI}$ class before $\mathrm{PCI}(\mathrm{OR}=$ 0.784 per 1 class increase, $95 \% \mathrm{Cl}: 0.65-0.945 ; p=0.01$ ) were considered to decrease the risk of this adverse event. No significant impact of rotablation was found $(\mathrm{OR}=7.201,95 \% \mathrm{Cl}: 0.968-53.562 ; p=0.054)$. Male gen$\operatorname{der}(\mathrm{OR}=7.502,95 \% \mathrm{Cl}: 2.045-27.523 ; p=0.002)$, age $(\mathrm{OR}=1.024,95 \% \mathrm{Cl}: 1.01-1.039 ; p=0.001)$, diabetes mellitus (OR $=1.609,95 \% \mathrm{Cl}: 1.13-2.291 ; p=0.008)$, cardiogenic shock at admission to the catheterization laboratory $(\mathrm{OR}=33.689,95 \% \mathrm{Cl}: 24.366-46.579 ; p=0.001)$, previous stroke $(\mathrm{OR}=1.834,95 \% \mathrm{Cl}: 1.072-3.138$; $p=0.03)$ and myocardial infarction in past medical history $(\mathrm{OR}=2.395,95 \% \mathrm{Cl}: 1.587-3.614 ; p=0.001)$ were significant predictors of periprocedural death. Arterial hypertension $(\mathrm{OR}=0.561,95 \% \mathrm{Cl}$ : 0.402-0.782; $p=0.001)$ and $\mathrm{TIMI}$ class before $\mathrm{PCI}(\mathrm{OR}=0.547$ per 1 class increase, $95 \% \mathrm{Cl}: 0.468-0.639 ; p=0.001)$ correlated negatively with the risk of mortality during $\mathrm{PCl}$.

\section{Discussion}

Patients with a lower risk profile were the most frequent candidates for BVS implantation. The presented results are consistent with the main criteria of the algorithm used for patient's qualification for Absorb BVS implantation (Figure $1 \mathrm{~B}$ ). To our best knowledge, this registry is to date the largest multicentre report of everyday usage of BVS in "real-world" settings. Indications for PCI with BVS were comparable to those reported in the GHOST-EU registry [9]. However, our registry included less ST-elevated myocardial infarction(STEMI)/non ST-elevated myocardial infarction (NSTEMI) in favor of patients with unstable angina. The safety and efficacy of BVS implantation with very good procedure results in both ACS and SA have been presented in several studies [9-13]. In our registry treatment of lesions in the middle and distal portion of the LAD was seen as a particularly strong indication for use of BVS over a metallic stent in order to reduce limitation in future $\mathrm{PCl}$ or bypass grafting by left internal mammary artery utilization. As previously suggested, younger patients were considered to have the greatest theoretical benefit over a permanent stent in cumulative reduction of the risk of late scaffold thrombosis (ScT) [13]. A similar observation regarding selection of patients and lesions for BVS implantation has been presented in a few large studies [2, 9]. Patient selection for 
BVS implantation in this registry was consistent with the main criteria of recommendations from both a European and a Netherlands consensus [14, 15], which indicate the highest beneficial effect on longtime clinical outcome after scaffold deployment. Procedural success depends not only on proper selection of patients but also lesions [16]. Several studies have suggested benefit from intracoronary imaging with IVUS and/or OCT for optimization of $\mathrm{PCl}$ results [17]. However, according to the European consensus it is not routinely recommended for this purpose [15]. Intravascular ultrasound is used for the evaluation of the plaque morphology and in the preparation phase. Optical coherence tomography allows better optimization of scaffold deployment. In addition, it could be more useful in complex lesions or bifurcations [18]. Several studies have presented high variability in intravascular imaging utilization during $\mathrm{PCl}$ with BVS deployment [9, 19-21]. Our registry showed lower frequency of OCT and IVUS utilization in comparison with most of the above-mentioned studies. However, rates of imaging use were similar to those reported in the previous Polish national registry of BVS implantation [2]. Vessel visualization with these procedures was not mandatory, but it was performed in difficult cases with a questionable result of scaffold deployment. According to the European consensus, the new users of BVS should have a lower threshold for the use of imaging before and after BVS implantation [15]. Increased risk of ScT and myocardial infarction were early concerns raised with introduction of BVS utilization. The GHOST-EU registry presented cumulative incidence of definite/probable ScT of $1.5 \%$ at 30 days and $2.1 \%$ at 6 months (most of the cases occurred during 30 days after $\mathrm{PCl}$ ) [9]. Further analysis revealed that 20 of 23 patients with ScT were on dual antiplatelet therapy (DAPT) at the time of thrombosis [22]. Early events were mostly attributable to procedural issues (i.e., dissection, incomplete scaffold apposition or expansion), and late events are more likely linked to scaffold-related factors and vascular responses [22]. The ScT rate after BVS delivery was also higher than for metallic stents in other "real-world" registries $3.0 \%$ in the AMC registry [23], 1.3\% in the Registro Absorb Italiano registry [24] preliminary data). However, the rate of ScT was not higher in the largest, most recent randomized controlled clinical trial [25]. Higher prevalence of thrombosis was reported in the first 30 days after implantation, similar to the frequency distribution for metallic stents [22]. To reduce the ScT rate, thorough selection of lesions and PCI techniques, more aggressive plaque modification before BVS implantation, routine high-pressure non-compliant balloon post-dilatation to ensure adequate scaffold expansion and more frequent use of intravascular imaging to optimize lesion coverage and scaffold dimensions was recommended $[22,26]$. On the other hand, extensive and time-consuming lesion preparation might lead to periprocedural myocardial infarction, coronary dissection or even vessel perforation [17]. In this registry incidence of perforation of coronary artery during BVS delivery was significantly higher in comparison with the metallic stent group. In the previous Polish national registry dissection occurred in $2.9 \%$ of all cases [2]. Another study demonstrated perforation of coronary arteries in $0.73 \%$ of included patients [27]. The results of our logistic regression analysis may support the idea of a possible impact of extensive lesion preparation before BVS implantation on increased risk of coronary artery perforation. In our study patients with a lower risk profile were the most frequent candidates for BVS implantation, which might be the reason for significantly lower periprocedural mortality in this group. This positive impact of BVS on periprocedural mortality was no longer significant after adjustment for covariates. Importantly, cardiogenic shock at admission to the catheterization laboratory was the strongest predictor of periprocedural death. A recent meta-analysis reported periprocedural myocardial infarction (according to the Society of Cardiac Angiography and Interventions criteria) in $0.8 \%$ of patients with BVS implantation [26]. In our study no periprocedural myocardial infarction was reported in the BVS group. The incidence of MI was low, probably due to inclusion of periprocedural events only. In a recent meta-analysis [28] patients treated with BVS implantation had a similar risk of myocardial infarction $(\mathrm{OR}=1.36,95 \% \mathrm{Cl}: 0.98-1.89 ; p=0.06)$ and death $(\mathrm{OR}=$ $0.95,95 \% \mathrm{Cl}: 0.45-2.00 ; p=0.89)$ but with higher risk of define/probable ScT (OR = 1.99, 95\% Cl: 1.00-3.98; $p=$ $0.05)$, especially between 1 and 30 days after implantation $(\mathrm{OR}=3.11,95 \% \mathrm{Cl}: 1.24-7.82 ; p=0.02)$ as compared to the metallic stent group [28]. However, Cassese et al. did not evaluate target vessel myocardial infarction (TVMI), which was significantly higher for BVS in comparison to conventional stents in data presented in two other meta-analyses [26, 29, 30]. Also, Cassese et al. did not discuss the numerically higher (but not statistically significant) prevalence of any-cause myocardial infarction in BVS patients $(5.2 \%$ vs. $3.5 \% ; p=0.06)$. Lipinski et al. also reported that patients who received a BVS were at a higher risk of myocardial infarction $(\mathrm{OR}=2.06,95 \% \mathrm{Cl}$ : $1.31-3.22, p=0.002)$ and definite/probable ScT (OR = $2.06,95 \% \mathrm{Cl}: 1.07-3.98, p=0.03)$ compared with the metallic stent group, whereas there was a lower (but not at the level of statistical significance) all-cause mortality with a BVS (OR $=0.40,95 \% \mathrm{Cl}: 0.15-1.06, p=0.06)$ [31]. This meta-analysis was limited by methodology that mixed SA and STEMI, single-arm registries and randomized trials, and included unpublished, non-peer reviewed registries $[22,30]$. In a recent patient-level, pooled meta-analysis of four randomized studies, TVMI was increased with BVS compared with DES (OR $=1.45,95 \% \mathrm{Cl}$ : $1.02-2.07 ; p=0.04)$, due in part to non-significant increases in periprocedural myocardial infarction and device thrombosis with BVS (OR $=2.09,95 \% \mathrm{Cl}$ : 0.92-4.75, $p=0.08$ ) [26]. The relative rates of all-cause and cardiac 
mortality and all-cause myocardial infarction did not differ between BVS and metallic stents [26]. Also data from the meta-analysis by Banach et al. were not able to detect statistically significant differences in 1-year outcomes between BVS and metallic stents [30]. The results showed significantly increased risk of TVMI between BVS and conventional stents $(\mathrm{OR}=1.45,95 \% \mathrm{Cl}: 1.03-2.05$; $p=0.03$ ) [29]. No other significant differences between BVS and conventional stents were reported except anycause myocardial infarction $(\mathrm{OR}=1.36,95 \% \mathrm{Cl}$ : $1.00-$ 1.85, $p=0.049$ ) [29]. Furthermore, BVS might provide intrinsically less kinetic support than metallic stents, especially 6 to 12 months after implantation when the radial strength is diminished as a consequence of resorption kinetics [31]. This might be responsible for the numerically higher risk of any-cause myocardial infarction with BVS versus metallic stents implantation and the significant increase of TVMI reported in a few metaanalyses. Furthermore, BVS might entrap more thrombotic content between the vessel and the scaffold, because of the larger wall surface coverage and the greater strut thickness than the current thin-strut DES [29]. On the other hand, it might lead to an increased incidence of ScT after BVS implantation. Administration of proper antiplatelet drugs seems to be crucial for optimal clinical results and a low rate of SCT after BVS implantation [29]. In a large "real-world" registry antiplatelet therapy was prescribed at discharge in all patients and recommended for at least 12 months in $93.6 \%$ of them [9]. Clopidogrel, prasugrel and ticagrelor were prescribed in $73.2 \%, 26.2 \%$ and $0.6 \%$ of patients, respectively [9]. A recent patient-level, pooled meta-analysis presented prasugrel or ticagrelor utilization in $24 \%$ of patients with BVS implantation [26]. A lower rate of newer antiplatelet drug administration during the procedure was reported in our registry in comparison with above-mentioned studies; however, newer antiplatelet agents were significantly more often administered in BVS implantation in comparison with DES/ BMS. This result is in line with current recommendations for antiplatelet therapy after BVS implantation [14, 15]. The present data might also be considered as a marker of preferences of BVS and antiplatelet therapy utilization in particular invasive cardiology centers in Poland.

The main limitation of this prospective observational study is its non-randomized design and all the known drawbacks of single-arm registry studies. The analysis included all available types of DES and BMS. Comparison with new-generation DES may be more appropriate to evaluate the safety and efficacy of BVS implantation. The possibility of the results being affected by unknown confounding factors cannot be excluded. There is a potential bias caused by the lack of in-hospital and long-term follow-up data in terms of clinical endpoints. There is a lack of angiographic data describing lesion type and morphology. Detailed data on device types and sizes were also not provided in the ORPKI registry.
The relatively small sample size of patients with BVS implantation and low incidence of adverse events suggest that our study should be considered exploratory and hypothesis generating.

\section{Conclusions}

Patients treated with BVS implantation presented an acceptable safety and efficacy profile in comparison with the DES/BMS group. Lower risk patients were the most frequent candidates for BVS implantation. Scaffold implantation might be associated with higher risk of coronary artery perforation. Periprocedural administration of ticagrelor/prasugrel and use of intravascular imaging were significantly higher in the BVS group in comparison with DES/BMS.

\section{Conflict of interest}

The authors declare no conflict of interest.

\section{References}

1. Windecker S, Kolh P, Alfonso F, et al. 2014 ESC/EACTS Guidelines on myocardial revascularization: the Task Force on Myocardial Revascularization of the European Society of Cardiology (ESC) and the European Association for Cardio-Thoracic Surgery (EACTS) Developed with the special contribution of the European Association of Percutaneous Cardiovascular Interventions (EAPCI). Eur Heart J 2014; 35: 2541-619.

2. Rzeszutko $七$, Siudak Z, Włodarczak A, et al. Use of bioresorbable vascular scaffolds in patients with stable angina and acute coronary syndromes. Polish National Registry. Kardiol Pol 2014; 72: 1394-9.

3. Giuseppe G, Ortega-Paz L, Brugaletta S, et al. Bioresorbable vascular scaffold implantation in acute coronary syndromes: clinical evidence, tips and tricks. Postep Kardiol Inter 2015; 11: 161-9.

4. Lesiak M, Araszkiewicz A. Leaving nothing behind: is the bioresorbable vascular scaffold a new hope for patients with coronary artery disease? Postep Kardiol Interw 2014; 10: 283-8.

5. Costopoulos C, Naganuma T, Latib A, et al. Looking into the future with bioresorbable vascular scaffolds. Expert Rev Cardiovasc Ther 2013; 11: 1407-16.

6. Rama-Merchan JC, Mattesini A, Dall'Ara G, Mario CD. Chronic total occlusion successfully treated with a bioresorbable everolimus-eluting vascular scaffold. Postep Kardiol Interw 2014; 10 : 128-9.

7. Serruys PW, Ormiston JA, Onuma Y, et al. A bioabsorbable everolimus eluting coronary stent system (ABSORB): 2-year outcomes and results from multiple imaging methods. Lancet 2009; 14: 897-910.

8. Ochała A, Siudak Z, Legutko J, et al. Percutaneous interventions in cardiology in Poland in the year 2014. Summary report of the Association of Cardiovascular Interventions of the Polish Cardiac Society AISN PTK. Postep Kardiol Interw 2015; 11: 177-81.

9. Capodanno D, Gori T, Nef H, et al. Percutaneous coronary intervention with everolimus-eluting bioresorbable vascular scaffolds in routine clinical practice: early and midterm outcomes from the European multicentre GHOST-EU registry. Eurolntervention 2015; 10: 1144-53.

10. Ielasi A, Cortese B, Varricchio A, et al. Immediate and midterm outcomes following primary $\mathrm{PCl}$ with bioresorbable vascular 
scaffold implantation in patients with ST-segment myocardial infarction: insights from the multicentre "Registro ABSORB Italiano" (RAl registry). Eurolntervention 2015; 11: 157-62.

11. Gori T, Schulz E, Hink U, et al. Early outcome after implantation of Absorb bioresorbable drug-eluting scaffolds in patients with acute coronary syndromes. Eurolntervention 2014; 9: 1036-41.

12. Felix CM, Onuma Y, Fam JM, et al. Are BVS suitable for ACS patients? Support from a large single center real live registry. Int J Cardiol 2016; 218: 89-97.

13. Rzeszutko $t$, Siudak Z, Tokarek T, et al. Twelve months clinical outcome after bioresorbable vascular scaffold implantation in patients with stable angina and acute coronary syndrome. Data from the Polish National Registry. Adv Interv Cardiol 2016; 12: 108-15.

14. Robaei D, Back LM, Ooi SY, et al. Everolimus-eluting bioresorbable vascular scaffold implantation in real world and complex coronary disease: procedural and 30-day outcomes at two Australian centres. Heart Lung Circ 2015; 9: 854-9.

15. Everaert B, Felix C, Koolen J, et al. Appropriate use of bioresorbable vascular scaffolds in percutaneous coronary interventions: a recommendation from experienced users. A position statement on the use of bioresorbable vascular scaffolds in the Netherlands. Neth Heart J 2015; 23: 161-5.

16. Karabulut A, Demirci Y. Cutting balloon use may ease the optimal apposition of bioresorbable vascular scaffold in in-stent stenosis. Postep Kardiol Interw 2015; 11: 64-6.

17. Tamburino C, Latib A, van Geuns RJ, et al. Contemporary practice and technical aspects in coronary intervention with bioresorbable scaffolds: a European perspective. Eurolntervention 2015; 11: 45-52.

18. Rizik DG, Hermiller JB, Kereiakes DJ, et al. The ABSORB bioresorbable vascular scaffold: a novel, fully resorbable drug-eluting stent: current concepts and overview of clinical evidence. Catheter Cardiovasc Interv 2015; 86: 664-77.

19. Caiazzo G, Kilic ID, Fabris E, et al. Absorb bioresorbable vascular scaffold: what have we learned after 5 years of clinical experience? Int J Cardiol 2015; 201: 129-36.

20. Costopoulos C, Latib A, Naganuma T, et al. Comparison of early clinical outcomes between ABSORB bioresorbable vascular scaffold and everolimus-eluting stent implantation in a real-world population. Catheter Cardiovasc Interv 2015; 85: E10-5.

21. Cortese B, lelasi A, Romagnoli E, et al. Clinical comparison with short-term follow-up of bioresorbable vascular scaffold versus everolimus-eluting stent in primary percutaneous coronary interventions. Am J Cardiol 2015; 116: 705-10.

22. Kimura T, Kozuma K, Tanabe K, et al. A randomized trial evaluating everolimus-eluting Absorb bioresorbable scaffolds vs. everolimus-eluting metallic stents in patients with coronary artery disease: ABSORB Japan. Eur Heart J 2015; 36: 3332-42.

23. Brie D, Penson P, Serban MC, et al. Bioresorbable scaffold A magic bullet for the treatment of coronary artery disease? Int J Cardiol 2016; 215: 47-59.

24. Kraak RP, Hassell ME, Grundeken MJ, et al. Initial experience and clinical evaluation of the absorb bioresorbable vascular scaffold (BVS) in real-world practice: the AMC Single Centre Real World PCI Registry. Eurolntervention 2015; 10: 1160-8.

25. Cortese B, lelasi A, Varricchio A, et al. Registro Absorb Italiano (BVS-RAI): an investigators-owned and -directed, open, prospective registry of consecutive patients treated with the absorb BVS: study design. Cardiovasc Revasc Med 2015; 16: 340-3.
26. Ellis SG, Kereiakes DJ, Metzger DC, et al. Everolimus-eluting bioresorbable scaffolds for coronary artery disease. N Engl I Med 2015; 373: 1905-15.

27. Stone GW, Gao R, Kimura T, et al. 1-year outcomes with the Absorb bioresorbable scaffold in patients with coronary artery disease: a patient-level, pooled meta-analysis. Lancet 2016; 387: 1277-89.

28. Ishibashi Y, Nakatani S, Sotomi Y, et al. Relation between bioresorbable scaffold sizing using QCA-Dmax and clinical outcomes at 1 year in 1,232 patients from 3 study cohorts (ABSORB Cohort $B, A B S O R B$ EXTEND, and ABSORB II). JACC Cardiovasc Interv 2015; 8: 1715-26.

29. Cassese S, Byrne RA, Ndrepepa G, et al. Everolimus-eluting bioresorbable vascular scaffolds versus everolimus-eluting metallic stents: a meta-analysis of randomised controlled trials. Lancet 2016; 387: 537-44.

30. Banach M, Serban MC, Sahebkar A, et al. Comparison of clinical outcomes between bioresorbable vascular stents versus conventional drug-eluting and metallic stents: a systematic review and meta-analysis. Eurolntervention 2016; 12: e175-89.

31. Lipinski MJ, Escarcega RO, Baker NC, et al. Scaffold thrombosis after percutaneous coronary intervention with ABSORB bioresorbable vascular scaffold: a systematic review and meta-analysis. JACC Cardiovasc Interv 2016; 9: 12-24. 